REVIEW ARTICLE 



\title{
Education and fertility in the context of rising inequality
}

\section{Alícia Adserà*}

\begin{abstract}
Two main factors arguably account for the fact that the negative gradient of fertility by educational attainment, which has been prevalent in developed countries in most of the 20th century, has recently become weaker in most Western countries: rising inequality and educational composition shifts that change the selectivity of educated mothers in terms of their preferences regarding career and children. In this paper I review how four drivers of inequality mediate the childbearing behavior of women of different educational backgrounds: first, the impact of rising employment polarization; second, the slowdown in gender convergence in labor participation and wages since the late 1990s; third, the fertility behavior of newly-arrived immigrants contingent on economic opportunities in destination countries; and fourth, widening gaps in resources children receive from parents with different levels of educational attainment. These gaps can have lasting intergenerational impact both in economic and social outcomes such as fertility and union formation.
\end{abstract}

\section{Introduction}

An extensive literature has highlighted the complexity of the relationship between education and fertility, and, particularly, how the childbearing behaviors of women with different educational backgrounds may vary depending on the social and economic context (Skirbekk 2008; Ní Bhrolcháin and Beaujouan 2012; Merz and Liefbroer 2017). This review considers an additional factor mediating fertility patterns: rising economic inequality in most developed nations, particularly in the U.S.

Economic and labor market conditions affect household choices in many dimensions, including parenthood, and may influence a couple's ability to attain their preferred family size. The constraints faced by a household when making those choices vary by educational attainment. In recent years, and particularly since the

\footnotetext{
* Alícia Adserà, A29 JRR Building, Princeton University, Princeton, 08544 NJ, USA Email: adsera@princeton.edu
} 
last recession of the late 2000s, economic inequality has been on the rise across most developed countries, most notably in the U.S. With increasing inequality, the types of constraints that matter for childbearing decisions among families with different levels of education may diverge even further than in the past.

To analyze how inequality might influence childbearing patterns, this review draws from the current understanding of the relationship between educational attainment and both fertility and fertility intentions (Van Bavel 2012; Testa 2014). As women (re)entered the labor force in large numbers during the latter decades of the 20th century - when their human capital became more valuable in the labor market - fertility continued to drop. Fertility was lowest among the mosteducated women, many of whom chose to devote more resources to each child rather than more time to childbearing, and thus reduced their family size. However, because fertility intentions among the most-educated remained relatively high, the gap between their intended and actual fertility became relatively wide in most countries (Testa 2014; Beaujouan and Berghammer 2017). Interestingly, new evidence, particularly since the recent Great Recession, suggests that there has been a gradual convergence in fertility rates among educational groups and a flattening of the existing negative educational-fertility gradient in some countries, such as the United States (Pew Research 2013 for the U.S.). In this study, I argue that this trend is likely driven in part by both economic inequality and the decreased selectivity of highly-educated women, as their share of the population has grown. Furthermore, I explore the factors that could cause this convergence to be long-lasting, and discuss the role of increasing inequality in fueling it.

Of the significant changes in economic distribution that have occurred across advanced countries in the last 20 years, four sources of inequality are among the most relevant for shaping recent trends in fertility. I examine two key dynamics in the labor market: first, recent structural changes in the labor market that have varying effects on workers with different levels of educational attainment; and second, the evolution of the gender wage gap (with a particular focus on U.S. data). Next, I explore how the fertility behavior of newly-arrived immigrants - mediated by the economic opportunities they are offered at their destination - may affect a country's educational gradient of fertility. Finally, I discuss the implications of widening gaps in human capital investments in children by parents with differing levels of educational attainment (again, with a particular focus on the U.S.). I conclude the article with an examination of how these inequality dimensions may shape the education-fertility relationship in the future.

\section{Are the fertility rates of different educational groups converging?}

Education is a key element in theories explaining fertility behavior. The existing literature has shown that there are multiple pathways through which education 
may affect childbearing decisions, and that the relative importance of these pathways varies over time and across contexts. More education is usually associated with having a higher income that could help support a larger family. Yet a high market return to women's education also increases women's labor market opportunities, and makes the trade-off between time spent working and time spent caring for children more expensive. Furthermore, compared to their less-educated counterparts, highly-educated women are generally better informed and empowered to make their own independent choices, and may have better access to family planning (see Skirbekk 2008).

\subsection{Fertility and education in a historical perspective}

An extensive literature has reviewed the relationship between education and fertility across history. However, this relationship has been difficult to evaluate due to a lack of proper measures of the educational attainment of mothers in earlier data. In a meta-analysis of research on the association between fertility and social status, Skirbekk (2008) noted that in societies that had not yet undergone the first demographic transition, higher household income (which was positively correlated with the husband's socioeconomic status) and higher fertility seemed to go hand-inhand: as having a higher income was found to be correlated with having more wealth and better health, it is probable that higher-income women were able to bear more children and obtain additional child care support if needed. Higher fertility was thus likely a marker of social status in married couples. In contrast, since the early 20th century, when educational data became more widely available, the historical data show a negative relationship between women's educational and fertility levels.

The causal direction of that relationship is difficult to establish, and is still a matter of debate. On the one hand, early childbearing may lead a woman to discontinue her education. In the context of a developed country, Cohen et al. (2011) employed data that tracked the 1964 birth cohort of Norwegian women from age 17 to age 39 to show that women who became mothers earlier were prone to leave (or to not even enter) long educational tracks. Likewise, in a study conducted in a less developed setting, Lutz and Skirbekk (2014) found evidence that African women tend to stop their education after they become pregnant. However, they argued that this pattern does not seem to be the main driver of the association between education and fertility. On the other hand, social norms that foster later marriage and childbearing provide women with the opportunity to stay in school longer and to increase their educational attainment. In an analysis in which they instrumented the age at marriage with the age at menarche, Ambrus and Field (2008) argued that later marriage caused higher educational attainment in rural Bangladesh, where child marriage is prevalent. Thus a policy restricting child marriages could result in higher educational attainment among girls, and in later births. Similarly, extending compulsory schooling may delay childbearing, as Skirbekk et al. 2004 showed in a study for Sweden. A third possibility is that preferences may affect both educational 
and childbearing choices. Stange (2011), for example, showed that among college students, women who would go on to have children early differed from other women in their educational behavior before they conceived; and therefore concluded that preferences may drive both first birth timing and educational trajectories.

Leaving issues of reverse causality aside, we note that since the first demographic transition, more-educated women have given birth to fewer children than their lesseducated peers. Since the late 19th and the early 20th centuries, several forces have led to the inversion of the relationship between social status (or education) and fertility. These forces include the slow but steady (re)entry of women into formal employment; rural to urban migration, which meant that women became detached from the extended family structures typical of agricultural settings that tended to support childrearing and lower the cost of working outside the home; and improvements in family planning, which first became available to the most-educated.

Goldin (2006) provided a very illuminating historical account of the changes in female labor force participation through the 20th century in the U.S. context, which resemble the changes that occurred in other rich countries. By the end of the 19th century, urbanization was accelerating, and there were more opportunities to work in blue-collar jobs. As women were finding it more difficult to combine childrearing with working than they had when living on the family farm, they retreated to the home environment. Because their husbands were earning relatively large incomes and working a "dirty" job was stigmatized, the majority of married women stayed out of the workforce. The blue-collar jobs available to women did not pay enough to compensate for the fixed costs of working away from home, particularly for women who had migrated to an urban area, and whose social networks had shrunk. Highly-educated women felt pressure to choose between work and family. Of the U.S. women who graduated from college between 1900 and 1920, around 30 percent never married; and of those who married, around 30 percent remained childless (Goldin 2004).

In the decades that followed, the educational attainment levels of women continued to rise, and women started to (re)enter the labor force in greater numbers. This trend is attributable to several factors, including improvements in household technologies, such as washing machines; the increased acceptance of women working in newly-available white-collar jobs; and the shock of World War II, during which large numbers of women took the places of absent men in the factories. Also during this period, marriage bans, or laws that effectively excluded married women from working in most positions in the labor market, were eliminated in the U.S.

With the labor market opportunities open to women growing, the expected returns to women's education were also rising. Galor and Weil (1996) noted that as the prevailing forms of employment in the economy shifted away from jobs that require more physical strength, and toward jobs that require a broader spectrum of skills, the value of women in the labor market and their potential wages increased. These sectoral and technological transformations had clear implications for childbearing patterns, as the microeconomic models of fertility of Becker (1960) and Willis (1974) indicated. 
In his 1960 article, "An Economic Analysis of Fertility," Becker modeled fertility choices as parental demand for children, and argued that these choices could be analyzed using standard consumer theory. According to this framework, women who are making fertility choices are constrained by factors such their economic and educational resources, social norms regarding family size and out-of-wedlock children, and the availability of family planning tools. A key initial insight in Becker's paper is the idea that the cost of raising children is partly endogenous, because the time the mother (or the parents) spends caring for children is valuable in the labor market. As the demand for women in the labor force increases, the relative wages of women also rise. If women are forgoing income to spend time caring for children, the opportunity cost of raising a child also increases. Although higher wages for women has a positive income effect that should drive up overall consumption (including demand for children), the move away from costly options (such as having children) and toward the consumption of goods could lead to lower fertility.

A second important insight of Becker's work is that the couple's utility can be derived from both the quantity of children and their quality (i.e. investments in their human capital, such as health or education); and that households may have different demand elasticities for quantity and quality. Therefore, an increase in a woman's wages (or, for that matter, any increase in the family's income) might be spent primarily on investments in individual children (quality), rather than on increasing the number of children. Willis (1974) developed a model of fertility that integrated Becker's quality-quantity tradeoff with a model of household production and human capital investment. The model predicted a negative relationship between income and fertility based on assumptions about the value of women's time and the quantity-quality interaction. Willis therefore predicted that fertility would decline more among highly-educated women than among less-educated women.

As women's barriers to entering the labor market were being lowered, sizable gains in life expectancy were being made. This implies that women had more time to reap the returns to their human capital investments, even after their children left home. Another factor that boosted female education and labor force participation was the increased divorce risk. As partnerships became less stable, women sought to improve their earning options in case of divorce by acquiring experience in the labor market (Stevenson 2008).

All of these educational and labor market choices were facilitated by the availability of modern contraception, which enabled women to control the timing of childbearing. Of the three preconditions for the sustained fertility decline identified by Coale (1973), access to technology for regulating fertility was the most important, as birth control enabled women to choose to have a smaller family. Historically, better educated women had greater access to contraception, and tended to use it more effectively than less-educated women (Lutz and Skirbekk 2014). During the late 1960s and the early 1970s - a period when large numbers of women entered the labor force in most post-transition countries - having access to the contraceptive pill lowered the costs of acquiring more human capital (college and beyond) and of 
starting a long-term career, because it reduced the risk of pregnancy. By exploiting variation over time across U.S. states in unmarried women's access to the pill, Goldin and Katz (2002) convincingly showed that having access to contraceptives delayed marriage, increased post-graduate education among women, reduced the desired number of children, and increased the fraction of never-married women with graduate degrees who were having sex. For the 1960-1975 period, Bailey (2006) studied the variation across the U.S. states in the legal right of unmarried women aged 18 to 21 to obtain the pill without parental consent. She found that the expansion of legal access to the pill led to significant reductions in the likelihood of becoming a mother before age 22, and to increased female labor force participation.

A development that followed naturally from the increase in women's educational attainment was that women who devoted more time to acquiring human capital were also likely to have postponed multiple adulthood transitions, such as work, household formation, and childbearing. Ní Bhrolcháin and Beaujouan (2012) reviewed a large sample of literature that looked at the role of education in late childbearing. They found that increases in rates of enrolment were partly responsible for the sharp rise in the mean age at first birth during the 1980s and the 1990s in Britain and in France. Similarly, in an analysis of the effects of a shift in educational policy in Sweden, Skirbekk et al. (2004) showed that a one-year increase in the school-leaving age had causal effects on the timing of childbirth.

Unsurprisingly, it has been found that while the postponement of childbearing deflates aggregate measures of fertility via the tempo effect, it can further reduce completed cohort fertility via social feedback effects on the timing of childbearing, whereby members of the cohort are influenced by the behavior of their peers (Kohler et al. 2002). With fewer years to complete their fertility and decreased fecundity later in life, many women fall short of their plans, and some may overestimate the capacity of ART to compensate for their rising infertility (Bewley et al. 2005). Postponement of the first birth has been singled out as a major explanation for the gap between desired and completed fertility. Because tertiary-educated women spend more time acquiring human capital than women with less education, they are also more likely to postpone childbearing (Morgan 2003; Quesnel-Valleé and Morgan 2003). Predictably, childlessness rates have historically been higher among the most-educated women; although the differences between the educational groups seem to be closing somewhat, at least in the U.S. (Goldin 2004, Bailey et al. 2014). In Europe, childlessness continues to be most common among women with very low or very high levels of education. The generally positive educational gradient in childlessness may be weakening in some countries (Miettinen et al. 2015), as the childlessness rates of less-educated women are becoming closer to those of mediumeducated women (Beaujouan et al. 2016).

\subsection{Selection and convergence?}

Even though the major forces reviewed above, such as the longer school enrolment periods and the higher rates of labor market participation among highly-educated 
women, seem to predict a negative educational gradient of fertility, recent data indicate a weakening of that relationship in some developed countries (see Pew Research Center 2013, Bailey et al. 2014 for the U.S.; Kravdal and Rindfuss 2008 for Sweden). It is likely that several forces are driving the trend toward a moderate degree of convergence across educational groups. As women's educational levels have been increasing, greater shares of women than of men in most developed countries are college-educated (OECD 2014; Van Bavel 2012). Across the EU countries, the average share of 30- to 34-year-old women with some tertiary education was 44\% in 2016 (Eurostat 2017). Data from the American Community Survey show that the majority of U.S. women aged 15-50 have at least some college education, and that the majority of births in the U.S. are to highly-educated women. In 2012 , fewer than $16 \%$ of new mothers had less than a high school diploma, and around $23 \%$ had a high school degree only. The remaining $61.6 \%$ of women aged 15 to 50 who had given birth in the previous 12 months had at least some college (ISCED 5-8). Around 19\% of new mothers had a college degree, and $10.6 \%$ had a graduate or professional degree (US Census Bureau 2014). Table 1 shows the shares of live births by mother's educational attainment level in 2015 for selected European countries (Eurostat 2017). The shares of new mothers with some tertiary education were close to or more than $40 \%$ in most countries; and in Sweden and Denmark, over half of new mothers had tertiary education.

The evidence that a rising share of mothers across rich countries has at least some tertiary education implies that highly-educated women are currently less selected in their household behavior and preferences than was the case when a much smaller share of women had tertiary education. This decrease in selectivity should weaken the educational gradient of fertility (Goldin 2004). The distribution of highly-educated women with respect to their desired family size and willingness to trade off work for family responsibilities is more representative of society as a whole today than in the past. Whereas, in the past, tertiary education automatically led to high income and social standing, today's outcomes are more heterogenous as a function of fields of study and career paths (Van Bavel 2012). Women with tertiary education may be overrepresented in fields in which the earnings tend to be lower (Charles and Bradley 2002). Interestingly, less-educated mothers may be more selected in their socioeconomic resources, fertility, and work preferences and behaviors today than in the past.

Recent data on cohort fertility in the U.S. points to increased convergence in fertility across educational groups. Bailey et al. (2014) divided a sample of U.S. women by educational quartiles (rather than by attained degree) to allow them to better compare women across different parts of the distribution over time. Their results indicated that the trend toward convergence in the number of children born to women in the top and the bottom quartiles of the educational distribution in the U.S. has accelerated in recent years. Among the 1970 cohort, the most educated women had an average of 1.7 children, while the least educated women had an average of 2.2 children - which represents the smallest gap in the 90 years studied. This reduction in the gap was driven in part by an increase in the number of children 
Table 1:

Shares of live births by mother's educational attainment in selected European countries, 2015

\begin{tabular}{lccc}
\hline & $\begin{array}{l}\text { Less than primary, } \\
\text { primary and lower } \\
\text { secondary education } \\
\text { (levels 0-2) }\end{array}$ & $\begin{array}{l}\text { Upper secondary } \\
\text { and post-secondary } \\
\text { non-tertiary education } \\
\text { (levels 3 and 4) }\end{array}$ & $\begin{array}{l}\text { Tertiary } \\
\text { education } \\
\text { (levels 5-8) }\end{array}$ \\
\hline Belgium & 17.3 & 38.3 & 44.4 \\
Czech Republic & 10.2 & 54.3 & 35.5 \\
Denmark & 14.4 & 34.4 & 51.2 \\
Estonia & 15.5 & 39.1 & 45.4 \\
Greece & 14.1 & 45.0 & 40.9 \\
Spain & 35.7 & 28.0 & 36.4 \\
Austria & 15.3 & 62.8 & 21.9 \\
Portugal & 29.5 & 31.8 & 38.6 \\
Finland & 14.6 & 40.4 & 45.0 \\
Sweden & 15.5 & 37.1 & 47.4 \\
Norway & 18.4 & 24.6 & 57.0 \\
\hline
\end{tabular}

Source: Eurostat database [demo_faeduc]. Accessed in March 2017 at http://ec.europa.eu/eurostat/web/ population-demography-migration-projections/births-fertitily-data/database. ISCED levels. Data for Belgium, Estonia, and Austria is for 2012.

born to the most-educated women. Moreover, among women in the 1970 cohort who were in the top quartile of the educational distribution, the childlessness rate was much lower (around 21.4\%) than it was for women who were born 10 or 20 years before, and it was much closer to that of women in the bottom quartile $(14.9 \%)$. Even though the gap in cohort fertility has narrowed in the U.S., the differences in the average age at first birth by education have been widening continuously starting with the 1940 s cohorts. For the 1970 cohort, the gap stands at 6.8 years, as the average age at first birth was 28.3 for women in the highest quartile and was 21.5 for women in the lowest quartile (Bailey et al. 2014).

Researchers have found evidence of convergence in fertility rates across educational groups in other contexts as well. In many European countries, higherorder births no longer display a negative educational gradient, particularly in settings where the trade-offs between work and family are tempered by familyfriendly institutions (Kravdal and Rindfuss 2008 for Sweden; Adserà 2011b across a large set of European countries). For example, Van Bavel (2014) found that during the recovery of Belgian fertility in the post-war period, a flattening of the educational gradient was instrumental to boosting births. Thus, if increasing levels of female education are accompanied by reforms in the labor market and the welfare state that lessen the penalties for combining work and family, we would expect to see the gradient continue to weaken in the near future (Myrskylä et al. 2009) 
During recent periods of economic uncertainty, such as during the Great Recession of the late 2000s, the need for households to have two incomes to sustain their expenditures increased the pressure on women to actively participate in the labor market. Across the OECD countries, fertility has decreased the most among those population groups who were hit hardest by the Great Recession: namely, young adults, people with low levels of education, and migrants. This trend has contributed to the current weakening of the educational gradient. Over the 2008-2012 period in the U.S., birth rates increased only among women in their forties, and decreased the most among the youngest and the least-educated women (Cherlin et al. 2013). According to a report by the Pew Research Center (2013), from 2008 to 2011 birth rates declined 13\% for women without a high school diploma, $11 \%$ for women with a high school diploma only, $8 \%$ for women with some college education, and only $7 \%$ for women with a B.A. degree or higher. A similar pattern can be found in the European data (Lanzieri 2013).

In addition to changes in the selection of the highly-educated and the uneven effects of economic shocks across educational groups, the reversal of gender inequality in educational attainment is bound to have an impact on union formation and fertility. Changes in the relative numbers of men and women with different educational levels will shape marriage markets. In turn, the types of men highly-educated women marry or partner with may affect their fertility choices, and, ultimately, their number of children. Van Bavel (2012) described in some detail the different pathways through which the reversal of the gender gaps in educational attainment can ultimately affect fertility via union formation. His two main hypotheses have implications for the education-fertility gradient. First, he posited that if homogamy increases as the number of educated women rises (see Blossfeld and Timm 2003), the partnerships of women at the top of the educational distribution may become more stable, and their fertility may increase. Second, hypogamy, which is also expected to rise, could have an ambiguous impact on the fertility of highly-educated women. If the less-educated men married to these women participate in the household chores more than they typically have in the past, these partnerships could boost fertility. However, union instability in hypogamous relationships may depress fertility. Thus, using a couple's perspective when analyzing fertility decisions is key to understanding the behavior of different groups of women and the evolution of the educational gradient.

So far, the focus of this study has been on actual fertility by educational level. However, the question of whether or not fertility intentions vary in the same ways as achieved fertility is fundamental to understanding the relationship between women's education and fertility. Across European countries, dispersion in stated preferences regarding family size has been found to be smaller than that of observed fertility differentials. Thus, the gap between desired and actual fertility varies substantially across Europe (Bongaarts 2001; Goldstein et al. 2003). Consistent with previous work (Bongaarts, 2001; Quesnel-Valleé and Morgan 2003), both Testa (2012) and Beaujouan and Berghammer (2017) find that, across educational groups, the shortfall in births is larger on average among highly-educated women in Europe. 
Understanding the reasons why highly-educated women fail to achieve their stated goals is central to predicting whether the observed flattening of the educational gradient in fertility is a temporary phenomenon, or whether it will continue in the future. In a recent study analyzing data from 27 European countries from the 2006 and 2011 Eurobarometer survey, Testa (2014) found that lifetime fertility intentions are higher in countries with higher average educational attainment. She argued that an interpretation of these findings is that, in these countries, the trade-offs faced by women when entering the labor market are tempered by good institutional and economic conditions. Thus, the income effect arising from higher human capital is more relevant in childbearing decisions in these contexts than where the familywork tradeoffs are more challenging. In addition, Testa found a similar positive relationship between intentions and education at the individual level. These findings indicate that across the most developed countries, highly-educated women continue to have relatively high fertility intentions - whether they realize these intentions or not hinges on their socioeconomic conditions.

\section{The educational fertility gradient and inequality}

\subsection{Labor market polarization and inequality}

During recent economic downturns, less- and medium-educated workers have been hit particularly hard by unemployment, and the sectoral distribution of employment has undergone important transformations in the richest countries. Polarization in the labor market has increased, as some middle-income jobs seem to be disappearing (Autor 2014b). This section explores how this change in the structure of the labor market could exert downward pressure on the fertility of medium- and less-educated couples, and could therefore lead to a further flattening of the educational gradient.

The economic conditions under which households make childbearing decisions have long been recognized as crucial for understanding fertility patterns. There has been a long-running debate on the question of whether fertility is boosted by good economic conditions, rising employment, and earnings; or whether women prefer to have children in times of job scarcity, when the opportunity costs of childbearing in terms of forgone wages are lower. It was generally agreed that patterns of procyclical fertility were dominant throughout much of the 20th century until Butz and Ward (1979) suggested that countercyclical fertility had emerged in the U.S. during the late 1960s, when women were entering the labor force in large numbers. Sobotka et al. (2011) have provided a comprehensive review of the literature on the impact of economic recessions in developed countries over the last century. Most of these studies found that fertility is procyclical, but that the long-run aggregate effects of recessions are small, and their impact on birth timing tends to be relatively short-lived.

Economic uncertainty may affect family decision-making in multiple ways. Both aggregate and individual unemployment shocks, as well as unstable employment 
conditions, may prompt families to delay or even forgo births (e.g. Adserà 2011a \& b; Kravdal 2002, Mills and Blossfeld 2005, Goldstein et al. 2013, Kreyenfeld and Andersson, 2014). In a set of papers, I showed that from the mid-1980s into the early 2000s, low fertility in OECD countries was associated with: 1) large gender gaps in unemployment rates (Adserà 2005); 2) long-term unemployment, which fueled the postponement of births among women in their twenties in particular (Adserà 2004); and 3) a high prevalence of unstable jobs in the form of short-term contracts, and a lack of part-time employment opportunities (Adserà 2011b). Transitions to second and third births were faster among women whose partner had a stable job, such as those in the public sector in Southern European countries, where unemployment was especially high (Adserà 2011b).

To understand whether recessions affected women of different educational backgrounds through different channels and with varying intensities, Adserà (2011a) studied the transition to a second birth across educational groups among women in 12 European countries using data from the European Community Household Panel (ECHP) and the 2006 Spanish Fertility Survey (obtaining similar findings). The ECHP data indicated that between 1992 and 2000, the transition to a second birth occurred later when the unemployment rate was high, not only among women who were unemployed but also among employed women, and among the least-educated women in particular. Women who held temporary jobs instead of permanent positions were also less likely to deliver a second child across all education groups, but the impact of precariousness was slightly greater for medium- and highlyeducated women who might have expected to have more job stability than for women with less education. Consistent with these expectations, the results showed that college-educated women with the least stable jobs (e.g. casual work, a job with no contract, a job with a fixed-term contract of less than a year) were most likely to delay having a second birth, and that job instability mattered more to them than the overall level of unemployment. Thus, during the 1990s, high unemployment likely contributed to the flattening the educational gradient of fertility, but job instability may have had the reverse or an ambiguous effect.

The depth and pervasiveness of the Great Recession of the late-2000s had important level and distributional impacts on demographic behavior. Berghammer and Adserà (2016) employed data on families in 21 European countries and the U.S. to study the prevalence of unemployment during the period among families of different educational backgrounds. The analysis uncovered a steep increase in the educational gradient in unemployment in the 2007-2013 period for all age groups. Furthermore, the study showed that the share of households in which both spouses were unemployed surged - a consequence of increased educational homogamy that concentrated risk at the bottom of the education ladder. Families in which both spouses were low -educated were doubly disadvantaged. These findings are consistent with the results of research by Schwartz (2010), which show that the rise in assortative mating is another mechanism behind the increase in household inequality across developed countries, and in the U.S. in particular. 
In the U.S., the recession disrupted household formation, and resulted in a rapid rise in the share of young adults who were living with their parents (Cherlin et al. 2013). Fertility rates dropped sharply over the 2008-2011 period, with the largest declines occurring among the least-educated (Pew Research Center 2013). In the 2007-2011 period, Fertility decreased the most in the U.S. states with the largest increases in unemployment in 2007-2009, and among people whose incomes were below the poverty level or were less than $150 \%$ of the poverty level (Cherlin et al. 2013). Birth rate patterns during this period were similar across Europe (Lanzieri 2013). Goldstein et al. (2013) showed that the onset of the economic crisis and the rise in unemployment resulted in significant declines in period fertility in many European countries, and interrupted the positive trends that had started in some of these countries. The fertility shock was particularly large among young adults and in the countries where joblessness increased the most, such as in Italy and Spain. Overall, the fertility changes brought about by the Great Recession continued to weaken the negative educational gradient in fertility.

A major characteristic of the recent recession is that it hit developed countries at a time when their labor markets were already undergoing rapid change with extensive consequences on their income distributions. Inequality had been rising before the recession, but it widened considerably in its aftermath. Autor (2014a, Figure 6a) has shown that between 1980 and 2012, the real hourly earnings of full-time employed U.S. men increased by around $20 \%$ for those with a bachelor's degree, and by around $56 \%$ for those with post-graduate education. Conversely, the earnings of men with less than a high school diploma or with a high school diploma dropped by $22 \%$ and $11 \%$, respectively, over the period. The earnings of men with some tertiary education but less than a bachelor's degree did not change. Women fared better, but the gains made by women without a college degree were very small. The relationship between education and employment (and labor force participation) displayed an increased divergence similar to that observed for earnings. Income inequality also rose within education groups.

A series of changes in the labor market explain this trend. First, skill-biased technical changes weakened the demand for less-skilled labor and increased the demand for more-educated workers with skills that complemented the new technologies. Second, increased globalization, which forced workers in developed countries to compete with cheaper labor from poorer countries, was a major driver of the decline in real wages at the bottom of the educational distribution. Furthermore, large institutional changes, such as extensive de-unionization and the spread of performance pay and bonuses, intensified earnings heterogeneity both across and within educational groups. Finally, major structural changes in production associated with the rise of robots disproportionately hurt workers with jobs that were easily displaced by those new technologies (see Lemieux 2008 for a more detailed discussion of each of these issues).

While the introduction of innovative technologies can increase overall productivity in the economy, such technologies are generally more complementary with skillsets common among educated workers, such as problem-solving and 
Figure 1:

Percentage changes in the share of hours worked in low-, middle-, and high-paying occupations over 1993-2010 by country

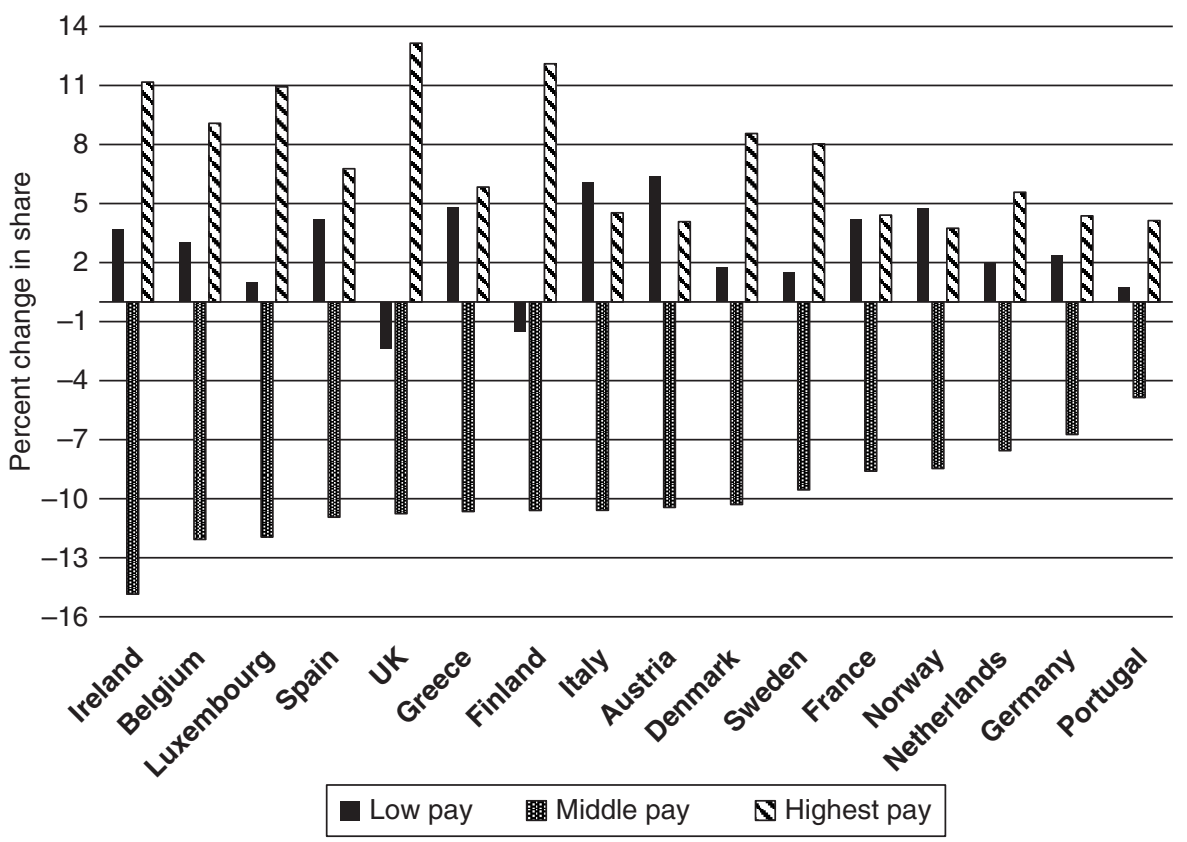

Source: Data from Goos et al. (2014, Table 2) and graph based on Autor (2014b). Data from the four lowest-paying occupations, the nine middle-paying occupations, and the eight highest-paying occupations in 1993.

creativity. As a result, the use of machines may amplify the differences in productivity across educational groups. Individuals with higher education can benefit from gains in productivity in ways that less-educated workers cannot. To better understand what types of positions were more threatened by the new changes in technology and globalization, Autor (2006) analyzed the skills required to undertake different jobs in the economy. His findings showed that routine jobs that were easily mechanized or could be cheaply off-shored to other countries were starting to disappear. Many of those positions - such as office or customer service clerks; or workers in precision, handicraft, craft printing, and related trades - are traditional middle-income jobs (Goos et al. 2014). At the same time, the shares of workers with less than a four-year college degree who were employed in more manual and less routine occupations was growing. As we can see in Figure 1, across all European countries between 1993 and 2010, the employment shares of the core middle-wage occupations shrank, whereas the shares of both low- and high-paying jobs rose, which resulted in increased job polarization and income inequality. Thus, some women and men with medium levels of education, or even with some college 
education, have been forced to accept much lower-paying (and potentially unstable) jobs than they had anticipated. This mismatch between workers' labor market expectations and available jobs, and its negative impact on household income, may exert downward pressure on fertility rates, particularly among individuals in the middle of the educational distribution. Furthermore, Autor et al. (2015) have shown that in the United States, negative shocks to male employment (mostly in traditionally well-paying manufacturing jobs) resulting from competition from Chinese imports significantly reduce marriage rates and fertility, while raising the shares of teen births and of poor and single-headed households. Thus, job polarization may exert downward pressure on the fertility of not just the leasteducated, but the medium-educated in particular.

\subsection{Pervasive gender wage gaps}

A second dimension of inequality in the labor market is the persistence of gender wage gaps (even among the highly-educated), despite large gains for women since the 1960s (Blau and Kahn 2000, 2016). Gender earnings inequality affects both the resources women (and their households) have at their disposal, and the incentives women have to trade time spent at work for family activities. In particular, gender wage gaps may differentially affect the childbearing choices of women across educational levels via the returns they receive from their human capital investments.

During the 1970s and the 1980s, the gender wage gap in most OECD countries decreased substantially. However, starting in the 1990s, the pace of progress made toward closing the earnings gap slowed, and then petered out. In the U.S., this pervasive gender wage gap has lingered at 75\%-83\% during the most recent decade, even among full-time workers (Bureau of Labor Statistics 2015). Across Europe, the average gender wage gap is around $83 \%$ (Eurostat 2015).

In a study of cohorts born between 1923 and 1978, Goldin (2014) noted that despite the great advances women have made over the last century, convergence in earnings is far from complete. In recent years, the earnings gap between U.S. college-educated women and men in full-time employment has been closing after hours of work and education are taken into account. The gap was well below 20\% when women born since the late 1950s entered the labor market in their early twenties, and was between $25 \%$ and over $40 \%$ for earlier cohorts at the same ages. However, the gap grew during the childbearing years of all of the cohorts in the study (reaching a maximum at around age 45), and never fully recovered to starting levels at later ages. For cohorts born since the late 1950s, the lifetime profile is flatter than for earlier cohorts (with a gap of around $35 \%$ by age 45 among those born in 1958, and a gap of around 60\% for cohorts born in the 1920s and the 1930s) (Goldin 2014, Figure 1B).

The literature points to two main forces that drive gender earning differentials. On the one hand, gender disparities in qualifications, hours worked, and type of 
occupation or sector result in wage discrepancies. On the other hand, the wage gap may be the outcome of discrimination.

Analyses of differences in worker characteristics have suggested that women may shy away from riskier or more physically demanding jobs that offer compensating differentials in the form of higher wages. In terms of qualifications, the formal educational attainment levels of women have risen continuously in recent decades, and now surpass those of men in most developed countries. This trend has led to substantial wage convergence. In addition to formal education, labor market experience is a key factor in a worker's remuneration; and within occupations, the gender gap in levels of experience is the single most important reason why men earn more than women (Blau and Khan 2000). Women tend to have lower levels of accumulated labor market experience than similarly educated men because women are more likely than men to make trade-offs between family and work. As Kravdal and Rindfuss (2008) reminded us, fertility is associated not just with childbirth, but, more importantly, with childrearing. Both women's and potential employers' expectations that women will have intermittent careers could also affect the types of occupations and sectors women are able or choose to enter, as well as their opportunities to participate in continuous on-the-job-training. Because of their lower levels of experience (or the presumption that they will work less in the future), women are less likely than men to be promoted to higher levels of the organization. In a recent analysis of the trends in the gender wage gap in the U.S. over the 1980-2010 period, Blau and Khan (2016) showed that conventional measures of human capital such as education and experience, combined with race, account for very small shares of the gender wage gap today. While the unadjusted difference in the female-to-male log wage ratio was around $79.3 \%$ in 2010 , adjusting for measures of human capital merely closed the gap to $82.1 \%$. The gap closed to $91.6 \%$ only after adding controls for industry and occupation, as well as unionization. However, $8.4 \%$ of the gap remained unexplained.

In a society where there are still clearly delineated differences in the division of work within the household, women may anticipate having to work a "second shift" even when they decide to enter the labor force. This heavy burden likely exerts downward pressure on fertility (Torr and Short 2004). The evidence regarding the degree to which fathers' contributions to child care and other household tasks have an impact on fertility has been mixed; and the results of such analyses depend on the context, the parity, and the specific tasks examined. Most analyses have found that men's contributions in the home are key to boosting fertility, particularly among highly-educated women, who are generally more committed to their careers (Cooke 2009; de Laat and Sevilla-Sanz 2011; Van Bavel 2012). However, some studies have found that the share of housework done by the male partner is irrelevant (see Craig and Siminski 2011 for second births in Australia).

Women with young children may adapt to the expectation of a "second shift" by choosing part-time work over full-time work, or by taking positions that allow for more flexible schedules and little overtime. These women either self-select or are pushed into more family-friendly jobs. Positions that are considered family-friendly, 
such as jobs in the public sector, may offer more employment security, but tend to be lower-paying than those that do not have as many benefits or have more demanding schedules.

Figure 2 shows that the estimated hazards rates to second and third births by a woman's labor force status in 13 European countries are the highest among women working part-time in the public sector (Adserà 2011b). The simulated proportion of women who have a second child within five years of the birth of their first child ranges from $52 \%$ for women working full-time in the private sector, to $60 \%$ for women who are inactive, to $62 \%$ for women working full-time in the public sector, and, finally, to $66 \%$ for women working part-time in a public sector job. Correspondingly, the gap between actual and intended fertility among Spanish women in 2006 was smallest among women in permanent positions in the public sector, and was largest among women in temporary jobs in the private sector (Adserà 2006).

Many of these women-friendly positions are in the fields of teaching or health care, and generally require relatively high levels of formal education (Martín-García and Baizán 2006). Van Bavel (2010) studied the impact of field of study and the share of female graduates in a sector on postponement of motherhood in Europe using data from European Social Survey in 21 countries. He found that among employees in sectors with relatively large shares of women (such as teaching and education), first births occur at earlier ages. Conversely, women entering sectors with relatively high entry wages and steep wage profiles, in which experience translates into higher earnings, tend to become mothers at later ages or to remain childless (Neyer et al. 2017).

These findings are consistent with Goldin's (2014) main argument that when more-educated women attempt to enter the high end of the labor market, they are confronted with the reality that in many high-paying sectors such as business or law, hourly wages increase with effort. Thus, the total earnings profiles are not linear with the number of hours worked, but are rather much steeper for those prepared to put in long hours. Given that labor market entry for college graduates coincides with the peak childbearing years, highly-educated women who are trying to "have it all," and are thus devoting time to both work and family, enter the labor force with a much flatter earnings profile than similarly-educated men. If some of these highlyeducated women want to continue to pursue careers in those sectors, they may find that they are compelled to giving up childbearing (or at least to postpone it until much later ages, when they might be able to negotiate part-time arrangements that are otherwise scarce in their sectors), and to put in long hours in the workplace in order to achieve the steeper wage profiles men enjoy. Since, as I discussed above, educated women may be less selected in their preferences for work today than in the past, childbearing patterns and hours of work within this group may be more heterogenous than ever before, and could depend on which career path these women choose. The ultimate effect on the education gradient in fertility of the forces discussed in this section may therefore be ambiguous. 
Figure 2:

Second and third birth hazards from the previous birth in 13 European countries by woman's labor force status, sector of employment, and full- or part-time employment relative to inactive women, $1994-2000$

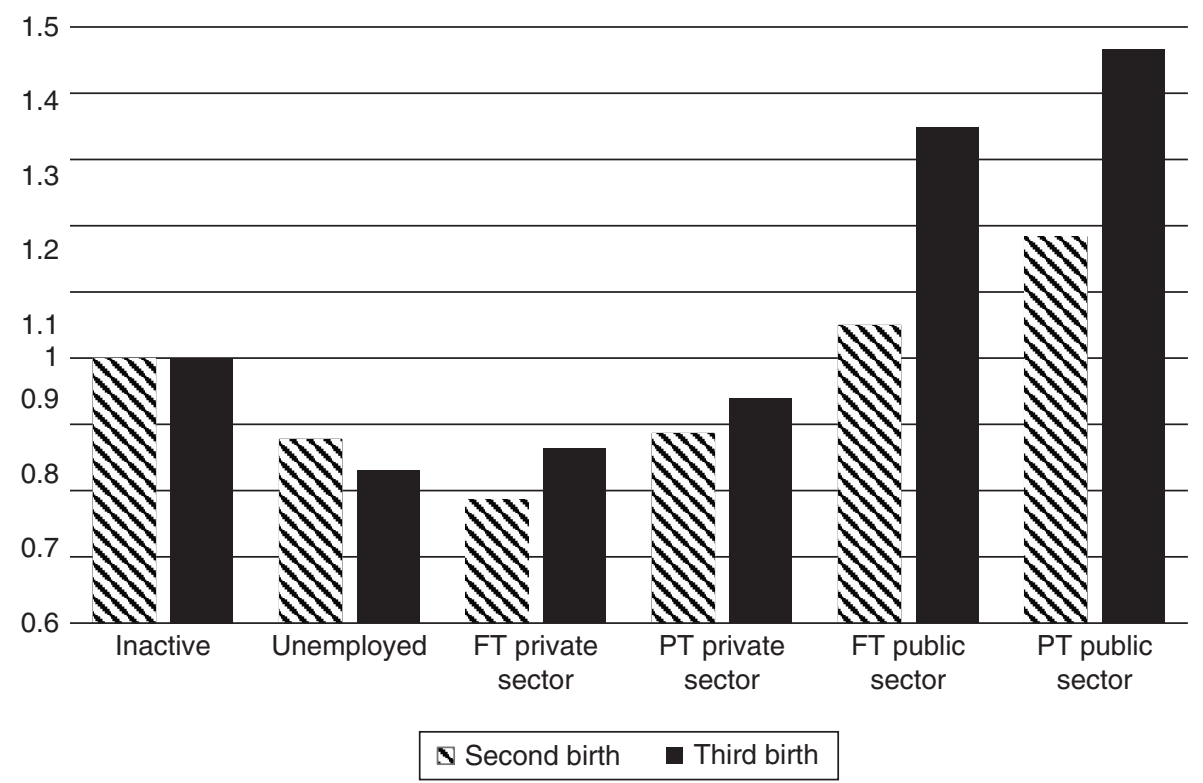

Source: Adserà (2011b). Estimates from Cox proportional hazard models to transitions to second and third births from the previous birth that include basic demographic controls (education of both spouses, marital status, migration background, income, age at first birth, and gender of previous children), as well as country labor market and maternity benefits controls. Monthly individual data from European Community Household Panel (ECHP) 1994 2000 of women who were 40 years old or under at the first interview, and who had given birth to their first or second child in January 1992 or after in 13 European countries (Netherlands, Belgium, Luxembourg, France, the United Kingdom, Ireland, Italy, Greece, Spain, Portugal, Austria, Finland, Sweden) from European Community Household Panel (ECHP) 1994-2000. Labor force status is lagged seven months. FT stands for full-time, and PT stands for part-time.

\subsection{Persistent fertility differences by migration background?}

Are the childbearing patterns of immigrants and their children different from those of native women? Most of the literature on immigrant fertility in highly-developed countries has shown that the fertility of immigrants tends to converge with that of the native-born population (Adserà and Ferrer 2014a, b). The recent economic crisis and the continuous rise in income inequality have exerted downward pressure on the economic status of immigrants, and thus on their birth rates across developed countries, particularly in the U.S. (Cherlin et al. 2013, Lanzieri 2013). The impact of those trends on the educational gradient of fertility in the destination countries is both ambiguous (as it depends on the degree of labor market integration of 
immigrant women, among other things) and likely relatively modest (i.e. similar to the net effect of immigrants on the period total fertility of most reception countries; Sobotka 2008).

When evaluating how increases in immigration are poised to affect the shape of family structure and fertility patterns in developed countries, two potential sources of inequality come to mind. On the one hand, immigrants may have childbearing patterns that differ from those in the most-developed countries. On the other hand, because the socioeconomic integration of immigrants as they enter the labor market and as their children join the educational system in their new setting also shape their future demographic behavior, rising inequality in the destination country may hamper this process.

The literature on immigrant fertility in rich countries has focused on three underlying mechanisms, which were first described in Goldstein and Goldstein (1981, 1983), that shape it: selection (whether those who migrate already resemble the destination population more than the population at origin), disruption (whether there is a temporary decrease in fertility before migration that is recuperated soon after arriving in the new destination), and adaptation to native fertility patterns over time in the country (see Adserà and Ferrer 2014b for a review).

Most studies on this topic have found that selection and adaptation lead to the convergence of immigrant fertility patterns with native patterns, particularly among members of the second generation, and in countries with more selective migration regimes that tend to receive relatively highly-educated immigrants (Anderson 2004; Bean et al. 2000; Choi 2014; Milewski 2007; Parrado and Morgan 2003; Georgiadis and Manning 2011; Coleman et al. 2012; Fernandez and Fogli 2006; Toulemon 2004, among many others). Nonetheless, there is some variation in the speed and the degree of convergence across countries of origin and contexts of reception (e.g. Anderson, 2004; Georgiadis and Manning, 2011), and the TFRs of immigrants across European countries are still higher than those of natives (Sobotka 2008).

In many countries, the convergence of native and immigrant fertility patterns also seems to occur within education groups, particularly in the upper end of the educational distribution. Adserà and Ferrer (2014a) showed that the fertility behavior of individuals who migrated as children (before age 18) to Canada and who attained tertiary education is similar to that of natives, regardless of their age at migration (between zero and 17). For child immigrants who do not reach the tertiary education level, age at migration matters, and those who arrived during their teenage years tend to have higher fertility than natives with similar characteristics (for an analysis of Canada, France, and the UK, see Adserà et al. 2012).

In rich countries with relatively large foreign-born populations, intermarriage rates have been increasing. Lanzieri (2012) showed that for the 2008-2010 period, the share of natives married to foreign-born individuals was between $6 \%$ and $7 \%$ in Germany, France, Austria, and Belgium; and was around 5\% in the UK, Sweden, and the Netherlands. What are the consequences of the increase in mixed marriages on fertility? On the one hand, as Van Bavel (2012) noted, intermarriage may be associated with increased marital instability, and thus with decreased fertility. Whether 
this instability is expected to be more or less widespread among the highly- or the less-educated is an open question, but since having a higher educational level is associated with having more information and being more open to cultural differences, it is possible that highly-educated mixed couples have low levels of union conflict, and thus have average levels of fertility. On the other hand, natives who believe in more traditional roles for women may choose to enter mixed unions and have larger families. This latter type of mixed marriage is likely more prevalent among lesseducated couples, and should strengthen a negative educational gradient of fertility.

A key factor in the evolution of fertility and household formation patterns among immigrants is how their economic position in the receiving society evolves over time and compares to their aspirations, as well as the types of jobs they hold and their level of female labor force participation. If immigrant women are more adapted to the local labor market, they may reduce their family size. Socialization through broader female participation in the recipient culture should exert downward pressure on their fertility. Yet, of the immigrants who are active on the labor market, the mosteducated may access more stable jobs with benefits that allow them to combine family and work more easily than their less-educated counterparts. This trend would contribute to the flattening of the aggregate educational gradient. Conversely, if the least-educated female immigrants remain outside of the labor market, they are more likely to maintain childbearing patterns close to those in their countries of origin. This trend would reinforce a negative gradient of education and fertility. The socioeconomic integration of immigrant women is also fundamental to the demographic behavior of subsequent generations, as mothers may serve as role models for their children.

During the recent Great Recession, foreign-born populations were hit particularly hard in most developed countries, and their unemployment rates increased more sharply than those of natives (Cherlin et al. 2013). As a result, immigrant fertility has declined in recent years. In the U.S., the sharp decrease in fertility among Hispanics has been largely attributed to the severe decline in the influx of new Mexican immigrants. But even if those flows had continued, the immigrants' fertility rates would have fallen in parallel to the decreases in the rates of natives (Cherlin et al. 2013). In Europe, the fertility rates of non-naturalized foreign-born populations decreased between 2009 and 2011, and in most countries, they declined more than the rates of natives (Lanzieri 2013).

\subsection{Unequal parental resources}

The gaps in the resources children receive from parents with different levels of educational attainment and different union statuses have widened, particularly in the U.S., with children born to less-educated single mothers being the most disadvantaged (McLanahan 2004; Perelli-Harris et al. 2010; McLanahan and Jacobsen 2014). A lack of childhood resources may adversely affect economic and fertility choices in adulthood, unless social policies are successful in limiting the 
intergenerational transmission of poverty and demographic behavior. This, in turn, could impact a society's future educational fertility gradient.

As the second demographic transition (SDT) unfolded, rates of cohabitation and out-of-wedlock childbearing climbed. Among the most-developed countries, the trend toward non-marital childbirth first started in the Nordic and in a few other Northern European countries, and was not homogeneous across education groups (Lesthaeghe, 2010). In many European countries, such as in France, cohabitation was more prevalent among the highly-educated before spreading to all groups. In the English-speaking countries, especially in the United States, the educational gradient of cohabitation was negative from the beginning.

Across rich countries, marriage rates have declined, but continued to be higher among college-educated women than among those without a high school diploma, even though the rising numbers of highly-educated women might have worsened their prospects in marriage markets where hypogamy was still relatively rare (Van Bavel 2012). While among U.S. women born around 1900 the least-educated were 10 to 15 percentage points more likely to ever marry by age 35 than those in the top educational quartile; the gap closed in the subsequent cohorts, rose again in the 1940-1950s cohorts, and has reversed in the latest cohorts (Bailey et al. 2014). Within these general trends, Kalmijn (2013) noted that the gradient for marriage (or stable union) varies with the degree of gender equality across the most-developed countries (with more-educated women being more likely to be married than lesseducated women in gender-equal countries), and with the degree of economic inequality (with educated men being more attractive in more unequal settings). A phenomenon that is concurrent with the relative increase in marriage rates among highly-educated women is the low prospects for a stable union or marriage (likely resulting in low fertility) among less-educated men (Van Bavel 2012), particularly in more unequal economies (Kalmijn 2013).

As the patterns of partnership formation changed, rates of non-marital childbearing increased. This trend started in the Nordic countries and in France, where it became widespread by the early 1990s; and then increased sharply elsewhere in Europe starting in the late 1990s. As in the case of marriage, nonmarital fertility rates differ by education, with more children being born outside of marriage to the least-educated women in most European countries, and, notably, in the U.S. (Perelli-Harris et al. 2010, McLanahan 2004, McLanahan and Jacobsen 2014, Bailey et al. 2014). The rise of cohabitation and non-marital fertility among the least-educated can be partly attributed to unemployment and job instability, which makes it difficult for couples to reach the high marriage bar they have set for themselves (Perelli-Haris et al. 2010; Kalmijn 2013; Cherlin et al. 2013; McLanahan and Jacobsen 2015). Perelli-Harris et al. (2010) studied the educational gradient of first births to cohabiting women relative to first births to married women in eight European countries since the 1970s. They found that the gradient is negative in most countries - except for Italy, where cohabitation is still emerging, and where the gradient thus has a U-shape. Still, in countries such as France, the highly-educated were the pioneers in childbearing within cohabitation in the 1970s 
Figure 3:

Shares of births to single and cohabiting mothers under age 40 by educational attainment; United States 2005-2009

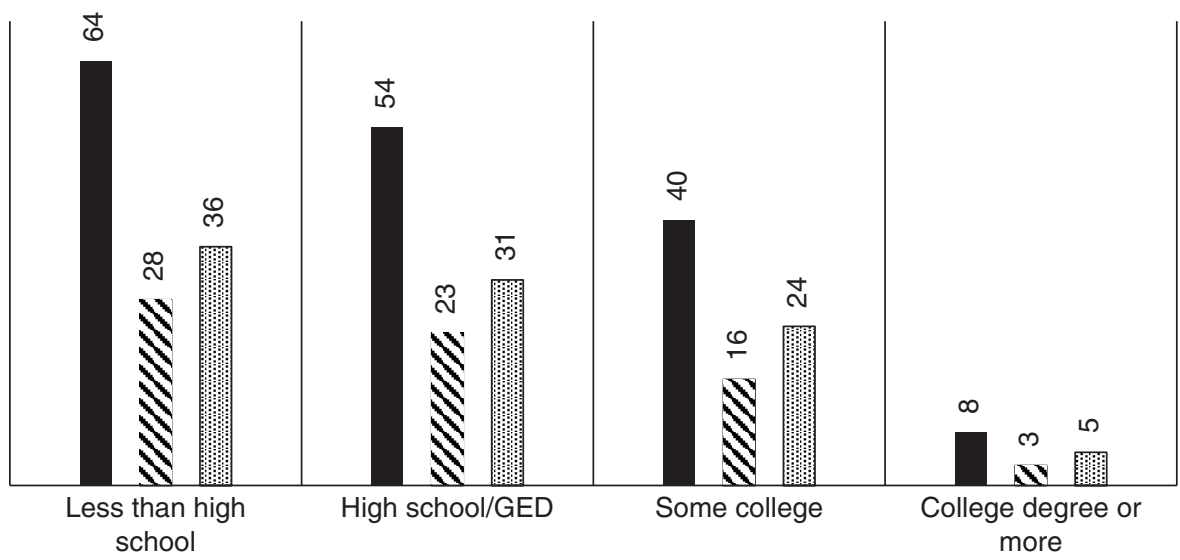

- Total non-marital $\mathbf{\Delta}$ Single $\quad$ 苚 Cohabiting

Source: Manning et al. (2014). Analysis using National Survey of Family Growth (NSFG) 2006-2010. High school or general education degree (GED) imply the completion of the upper secondary education level, which is the ISCED 2011 (International Standard Classification of Education) level 3; some college corresponds to levels 4-5; and college degree or more implies the completion of at least level 6. Retrieved from National Center for Family \& Marriage Research in November 2016 at https://www.bgsu.edu/content/dam/BGSU/college-of-arts-and-sciences/ NCFMR/documents/FP/FP-14-05_TrendsInBirths.pdf.

and the 1980s, and the gradient did not shift until the end of the 1990s. Among single women, the education gradient is strongly negative in all countries. PerelliHarris et al. (2010) conclude that the SDT alone cannot explain those patterns, but rather the SDT combined with some of the economic constraints I discussed in previous sections. In the U.S. case, the shares of births to single and cohabiting mothers by education for the 2005-2009 period display a steep negative gradient (Figure 3). While 64\% of births to women with less than a high school diploma happened outside of marriage ( $28 \%$ among single women), the corresponding share for those with college degrees was only $8 \%$ (3\% among single women). These rates stood at 43\% and 5\% in 1980-84 (Manning et al. 2014). Furthermore, less-educated women are becoming mothers at earlier ages. In 2011, around $45 \%$ of new U.S. mothers with a high school diploma or less were younger than age 25 , while the corresponding rate for college graduates was 3\% (Pew Research Center 2013).

These demographic changes have resulted in an increasing divide in the amount of parental resources children receive, which is linked to a large extent with differences in the educational attainment levels, ages, and marital statuses of their parents (McLanahan 2004). Lundberg and Pollak (2014) noted that while some highly-educated couples may cohabit before entering marriage, they typically have 
children within relatively stable marriages in the U.S. (and in long-term unions in Europe, where cohabitation is more widely accepted and stable). For highlyeducated parents who devote considerable resources of time and money into raising their children, a stable union is the commitment mechanism that enables such investments. The amounts of time both fathers and mothers spend caring for their children under five, and the amounts of money they spend per child, have increased since the early 1970s, particularly among the college-educated and households in the top income quartile (Lundberg and Pollak 2014). Similarly, maternal education in the U.S. is positively associated with time devoted to different forms of child care across ages zero to 13 (Kalil et al. 2012).

As McLanahan (2004) pointed out, the unequal educational, material, and emotional resources that children in different types of families receive sets them on different paths that continue into adulthood. These diverging destinies are mainly the result of rising inequality, and can in turn contribute to the persistence of inequality through intergenerational continuities (McLanahan and Percheski 2008). Of the children born outside of marriage, those born to less-educated single mothers are the most vulnerable, as they are at risk of having low educational attainment, of entering the labor market at the low end with a series of unstable jobs, and of becoming a parent while young and unmarried. Despite their tendency to have children early, the absence of a stable partnership and the lack of economic resources may depress the fertility of less-educated women (and men), and may thus strengthen the convergence in fertility across educational groups.

Although births outside of marriage are widespread in most parts of Europe, including in the Nordic countries, they are not as closely associated with large social status disadvantages as they are in the United States. Whether or not being born to unmarried parents negatively affects a child's outcomes depends to a large extent on the workings of the welfare state and on the stability of the union.

\section{Inequality: implications for the future of the fertility educational gradient}

The negative gradient of fertility by educational attainment that was prevalent during most of the 20th century seems to have weakened in developed countries. Even though more-educated women still have fewer children and are more likely to fall short of their intentions than their less-educated counterparts, the gap in the number of children born to these groups has shrunk. In this article, I have suggested some mechanisms that could underlie this apparent convergence, such as the depth of the Great Recession and rising inequality; as well as the decline in the social status selectivity of high-educated mothers in terms of their preferences regarding career and children, which is due to the sharp increase in the share of the population with post-secondary education. Among these mechanisms, this study has examined how different drivers of inequality could mediate the childbearing behavior of women of different educational backgrounds. Here, I briefly review how each of those 
sources of inequality could sway the education-fertility relationship in the future. Furthermore, I outline some policy implications for the labor market integration of both women and immigrants, and describe the role of social policy in moderating the intergenerational persistence of poverty.

First, I have discussed how the least- and mid-educated have been particularly affected by the recent Great Recession, and by rising employment polarization. Whether or not these structural changes in the labor market continue to interfere with the childbearing plans of households at the bottom of the educational distribution will determine the persistence of the fertility convergence. The trend toward young adults returning to (or staying in) their parental home has yet to stop, at least for young women (Cherlin et al. 2013). It has become more difficult for lessand medium-educated men (and women) to sustain what are generally considered "good" jobs, with relatively high levels of pay, stability, and benefits. Some routine jobs that can easily be off-shored or mechanized are disappearing, while the relative demand for more manual and more abstract jobs at either end of the income distribution is increasing (Autor 2014b). This loss of "jobs in the middle" affects not only medium-educated workers, but also some university graduates in particular fields who may have to adapt their career and childbearing plans accordingly. If their job aspirations and plans to make large investments in their children's human capital endure, they may have to adjust their family size downward. Such a trend would lead to further convergence in fertility levels across educational groups, or even to the appearance of a U-shaped relationship between education and fertility - which has already been observed to some extent in previous economic crises (e.g. in the transition to third births by education in Europe during the 1990s, Adserà 2011b).

Second, gender convergence in labor participation and wages has stalled since the late 1990s. Even after adjusting for traditional human capital variables, such as education (in which women are now at a relative advantage) and experience, the unexplained gender wage gap is still substantial, and is driven largely by differences in occupations and sectors (Blau and Khan 2016). Wages in the high-end professions to which many highly-educated women aspire tend to increase non-linearly with hours of work, and thus elicit a commitment of extended worktime (Goldin 2014). As a result, some women find themselves - either by choice or because of their cumulated employment and childbearing history - in professions that temper the trade-offs between work and family, but that pay less and limit their progress within the firm hierarchy. The heterogeneity of career trajectories among highlyeducated women may pull their fertility in different directions, making it difficult to predict the ultimate impact on the education fertility gradient. Women who work in demanding positions at the top of the labor market may be able to sustain fertility levels close to those of women in more family-friendly jobs by either postponing childbearing or by outsourcing child care (Raz-Yurovich 2014). As life expectancy rises and families become smaller, institutions need to level the playing field for women so that the whole society benefits from the long-term returns to their human capital investments. Labor market institutions may become more friendly as more educated women gain political power, and change the incentives in the workplace 
to promote overall gender equality, and to avoid penalizing women early in their careers who choose to devote time to childrearing (Myrskylä et al. 2009, Van Bavel 2012). Finally, men need to support this process by doing more housework and by adjusting their own labor market choices (de Laat and Sevilla-Sanz 2011; Van Bavel 2012, Esping-Andersen 2017).

Third, I have noted that if migrant fertility patterns continue to converge with those of the native-born population, immigrant inflows should neither greatly affect the educational gradient of fertility nor total fertility. Sobotka (2008) showed that the net effect of immigrants coming from high-fertility countries on the period total fertility of most of the receiving countries in Europe is relatively small, ranging from 0.05 to 0.10 in absolute terms. However, if there are large shifts in the composition of the migrants or if the economic barriers they encounter upon arrival (in part due to rising inequality) are large, their future patterns of fertility would be harder to forecast. Nonetheless, even if the origins of the migrants change dramatically, most sending countries are also experiencing large and rapid decreases in fertility (see the case of Mexico, for example). Thus, the idea of migrant fertility patterns "converging" with native patterns is starting to become outdated, even though there are still a few sending countries, such as those in sub-Saharan Africa, in which the period TFRs remain above the replacement-level threshold. Migration policy will be key in determining the selectivity of immigrants and their educational composition, as has been observed in contexts such as Canada (Adserà and Ferrer 2014a and 2014b). Finally, national policies that foster immigrant female labor force participation and women's socioeconomic integration by giving these women access to good jobs and enabling them to combine work and family may strengthen the compression of fertility rates across educational groups at the country level.

Finally, I argue that inequality in childhood conditions can be more consequential and can lead to lasting diverging destinies in countries where intergenerational mobility levels are low, and where access to educational resources and high-quality schools is strongly linked to household income, such as in the U.S. In those settings, the gaps in non-marital fertility and the average age at first birth between the top and the bottom of the education ladder are bound to persist over time. Public policy can moderate the impact of initial conditions for the future of the next generation. Universal benefits based on individual needs (as in Scandinavian and other European countries), rather than on family (means-tested) eligibility encourage work-family balance, strengthen union stability, and improve children's future chances (McLanahan 2004). Unstable partnerships, the scarcity of good jobs, and the low marriageability of less-educated men could exert downward pressure on completed fertility among the least-educated, and could contribute to the continuous convergence of family sizes across educational attainment levels (Perelli-Haris et al. 2010, Kalmijn 2013, Cherlin et al. 2013, McLanahan and Jacobsen 2015). Policies that foster the employability of less-educated men (and women) and provide more resources to households at the bottom may lessen these dynamics, and reduce inequalities among children. 


\section{References}

Adserà, A. 2004. Changing fertility rates in developed markets. The impact of labor market institutions. Journal of Population Economics 17: 17-43.

Adserà, A. 2005. Vanishing children: From high unemployment to low fertility in developed countries. American Economic Review 95(2): 189-193.

Adserà, A. 2006. An economic analysis of the gap between desired and actual fertility: The case of Spain. Review of Economics of the Household 4(1): 75-95, March.

Adserà, A. 2011a. The interplay of employment uncertainty and education in explaining second births in Europe. Demographic Research 25: 513-544.

Adserà, A. 2011b. Where are the babies? Labor market conditions and fertility in Europe. European Journal of Population 27: 1-32.

Adserà, A., A. Ferrer, W. Sigle-Rushton and B. Wilson (2012). Fertility patterns of child immigrants: Age at immigration and ancestry in comparative perspective. In The ANNALS of the American Academy of Political and Social Science, eds M. Tienda and A. Adserà, September 643(1): 134-159.

Adserà, A. and A. Ferrer 2014a. Fertility adaptation of child migrants to Canada. Population Studies 68(1): 65-79.

Adserà, A. and A. Ferrer 2014b. Immigrants and demography: Marriage, divorce, and fertility. In Handbook on the Economics of International Migration, eds B. R. Chiswick and P. W. Miller, for the Handbooks in Economics Series, Kenneth J. Arrow and Michael D. Intriligator, Volume 1. Elsevier B.V.

Ambrus, A. and E. Field 2008. Early marriage, age of menarche, and female schooling attainment in Bangladesh. Journal of Political Economy 116(5): 881-930.

Anderson, Gunnar 2004. Childbearing after migration: Fertility patterns of foreign-born women in Sweden. International Migration Review 38(2): 747-774.

Autor 2006. The polarization of the U.S. labor market. American Economic Review Papers and Proceedings 96(2): 189-194, May 2006 (with Lawrence F. Katz and Melissa S. Kearney).

Autor, David 2014a. Skills, education and the rise of earnings inequality among the other 99 percent. Science 344(6186): 843-851, 23 May 2014.

Autor, David 2014b. Polanyi's paradox and the shape of employment growth. Proceedings of the federal reserve bank of Kansas city, Jackson Hole Economic Policy Symposium (August 2014), 129-177.

Autor, David, David Dorn, and Gordon H. Hanson 2015. The labor market and the marriage market: How adverse employment shocks affect marriage, fertility, and children's living circumstances. MIT Working Paper.

Bailey, Martha J. 2006. More power to the pill: The impact of contraceptive freedom on women's lifecycle labor supply. Quarterly Journal of Economics 121: 289-320.

Bailey, Martha J., Melanie Guldi and Brad J. Hershbein 2014. Is there a case for a second demographic transition? Three distinctive features of the post-1960 U.S. fertility decline. NBER Chapters. In Human Capital in History: The American Record, 273-312. National Bureau of Economic Research, Inc. 
Bean, F., C. Swicegood, and R. Berger 2000. Mexican-origin fertility: New patterns and interpretations. Social Science Quarterly 811: 404-420.

Beaujouan, Éva, Zuzanna Brzozowska, and Kryštof Zeman 2016. The limited effect of increasing educational attainment on childlessness trends in twentieth-century Europe, women born 1916-65, Population Studies 70(3): 275-291.

Beaujouan, Éva and Caroline Berghammer 2017. The gap between lifetime fertility intentions and completed fertility in Europe and the United States: A cohort approach, Working paper, VID.

Berghammer, Caroline and Alícia Adserà 2016. Inequality between families after the great recession: The education gap in unemployment across Europe and in the United States, mimeo. Princeton University.

Bewley, Susan, Melanie Davies, and Peter Braude 2005. Which career first? The most secure age for childbearing remains 20-35. British Medical Journal 331(7517): 588-589.

Blau, Francine D. and Lawrence M. Kahn 2000. Gender differences in pay. Journal of Economic Perspectives Fall 75-99.

Blau, Francine D. and Lawrence M. Kahn 2016. The gender wage gap: Extent, trends, and explanations. IZA DP No. 9656. January.

Blossfeld, H. P. and A. Timm 2003. Who Marries Whom? Educational Systems as Marriage Markets in Modern Societies. Dordrecht: Kluwer.

Bongaarts, J. 2001. Fertility and reproductive preferences in post-transitional societies. Population and Development Review 27: 260-281.

Bureau of Labor Statistics 2015. Highlights of women's earnings in 2014, BLS reports, REPORT 1058, November. http://www.bls.gov/opub/reports/womens-earnings/archive/ highlights-of-womens-earnings-in-2014.pdf.

Butz, W. and M. Ward 1979. The emergence of countercyclical U.S. fertility. American Economic Review 69: 318-328.

Charles, M. and K. Bradley 2002. Equal but separate? A cross-national study of sex segregation in higher education. American Sociological Review 67(4): 573-599.

Cherlin, A., E. Cumberworth, S. P. Morgan, and C. Wimer 2013. The effects of the great recession on family structure and fertility. The ANNALS of the American Academy of Political and Social Science 650: 214-231.

Choi, K. 2014. Fertility in the context of Mexican migration to the United States. Demographic Research 30(24): 703-738.

Coale, A. J. 1973. The demographic transition reconsidered. In International Population Conference. Liège, 1973, Volume I, pp. 53-72. Liège, Belgium: International Union for the Scientific Study of Population.

Cohen, J. E., Ø. Kravdal and N. Keilman 2011. Childbearing impeded education more than education impeded childbearing among Norwegian women. Proceedings of the National Academy of the United States of America 108(29): 11830-11835.

Coleman D., P. Compton and J. Salt 2002. Demography of migrant populations: The case of the United Kingdom. In The Demographic Characteristics of Immigrant Populations, eds W. Haug, P. Compton and Y. Courbage, 497-552 (Population Studies No. 38). Strasbourg: Council of Europe. 
Cooke, L. 2009. Gender equity and fertility in Italy and Spain. Journal of Social Policy 38(1): 123-140.

Craig, Lyn and Peter Siminski 2011. If men do more housework, do their wives have more babies? Social Indicators Research 101(2): 255-258.

de Laat, J. and A. Sevilla 2011. The fertility and women's labor force participation puzzle in OECD countries: The role of men's home production. Feminist Economics 17(2): 87-119, Taylor \& Francis Journals.

Esping-Andersen, G. 2017. Education, gender revolution, and fertility recovery. Vienna yearbook of population research 2017(15): xx-Xx.

Eurostat. 2015. The gender pay gap in the European union, European commission, 2015. Accessed http://ec.europa.eu/justice/gender-equality/files/gender_pay_gap/gpg_eu_ factsheet_2015_en.pdf.

Eurostat 2017. Eurostat database. Accessed in March 2017 at http://ec.europa.eu/eurostat/ data/database.

Fernandez, R. and A. Fogli 2006. Fertility: The role of culture and family experience. Journal of the European Economic Association.

Georgiadis, A. and A. Manning 2011. Change and continuity among minority communities in Britain. Journal of Population Economics 24: 541-568.

Galor and Weil 1996. The gender gap, fertility, and growth. The American Economic Review 86(3): 374-387.

Goldin, C. 2004. The long road to the fast track: Career and family. Annals of the American Academy of Political and Social Science 596(1): 20-35.

Goldin, C. 2006. The quiet revolution that transformed women's employment, education, and family. American Economic Review 96(2): 1-21.

Goldin C. A. 2014. Grand gender convergence: Its last chapter. American Economic Review 104(4): 1091-1119.

Goldin, C. and L. Katz 2002. The power of the pill: Oral contraceptives and women's career and marriage decisions. Journal of Political Economy 110(4): 730-770.

Goldstein, Joshua, Michaela Kreyenfeld, Aiva Jasilioniene, and Deniz Dilan Karaman Örsal 2013. Fertility reactions to the 'great recession' in Europe: Recent evidence from orderspecific data. Demographic Research 29: 85-104.

Goldstein, Joshua R. and Catherine T. Kenney 2001. Marriage delayed or marriage forgone? New cohort forecasts of first marriage for U.S. women. American Sociological Review 66(4): 506-519.

Goldstein, J., W. Lutz and M. R. Testa 2003. The emergence of sub-replacement fertility ideals in Europe. Population Research and Policy Review 22(5-6): 479-496.

Goldstein, S. and A. Goldstein 1981. The impact of migration on fertility: an 'own children' analysis for thailand. Population Studies 35: 265-284.

Goldstein, S. and A. Goldstein 1983. Migration and fertility in peninsular Malaysia: An analysis using life history data. Santa Monica, CA: RAND Corporation.

Goos, Maarten, Alan Manning and Anna Salomons 2014. Explaining job polarization: Routine-biased technological change and offshoring. American Economic Review 104(8): 2509-2526. 
Juhn, Chinhui and Kristin McCue 2017. Specialization then and now: Marriage, children, and the gender earnings gap across cohorts. Journal of Economic Perspectives 31(1): 183-204.

Kalil, Ariel, Rebecca Ryan, and Michael Corey 2012. Diverging destinies: Maternal education and the developmental gradient in time with children. Demography 49(4): 1361-1383.

Kalmijn M. (2013). The educational gradient in marriage: A comparison of 25 European countries. Demography 50(4): 1499-1520.

Kohler, H. P., F. C. Billari and J. A. Ortega 2002. The emergence of lowest-low fertility in Europe during the 1990s. Population and Development Review 28(4): 641-680.

Kravdal, Øystein 2002. The impact of individual and aggregate unemployment on fertility in Norway. Demographic Research 6: 263-293.

Kravdal, Ø. and R. R. Rindfuss 2008. Changing relationships between education and fertility: A study of women and men born 1940 to 1964. American Sociological Review 73(5): 854-873.

Kreyenfeld, M. and G. Andersson 2014. Socioeconomic differences in the unemployment and fertility nexus: Evidence from Denmark and Germany. Advances in Life Course Research 21: 59-73.

Lanzieri, Giampaolo 2012. Merging populations: A look at marriages with foreign-born persons in European countries. Statistics in Focus 29/2012. Luxembourg: Eurostat.

Lanzieri, Giampaolo 2013. Towards a 'baby recession' in Europe? Differential fertility trends during the economic crisis. Statistics in Focus, Eurostat 13/2013.

Lemieux, Thomas 2008. The changing nature of wage inequality. Journal of Population Economics 21(1): 21-48.

Lesthaeghe, R. 2010. The unfolding story of the second demographic transition. Population and Development Review 36(2): 211-251.

Lundberg, Shelly and Robert A. Pollak 2014. Cohabitation and the uneven retreat from marriage in the U.S., 1950-2010, NBER Chapters. In Human Capital in History: The American Record, 241-272. National Bureau of Economic Research, Inc.

Lutz, W. and V. Skirbekk 2014. How education drives demography and knowledge informs projections (Chapter 2). In World Population and Human Capital in the Twenty-First Century, eds Wolfgang Lutz, William P. Butz and KC Samir. Oxford University Press.

Manning, W. D., S. L. Brown, E. Lamidi and K. K. Payne 2014. Trends in births to single and cohabiting mothers, 1980-2009. (FP-14-05). National Center for Family $\mathcal{G}$ Marriage Research. Retrieved from https://www.bgsu.edu/content/dam/BGSU/college-of-arts-and-sciences/NCFMR/ documents/FP/FP-14-05_TrendsInBirths.pdf.

Martín-García, T. and P. Baizán 2006. The impact of the type of education and of educational enrolment on first births. European Sociological Review 22(3): 259-275.

McLanahan, S. 2004. Diverging destinies: How children fare under the second demographic transition. Demography 41(4): 607-627.

McLanahan, S. and C. Perchewski 2008. Family structure and the reproduction of inequalities. Annual Review of Sociology 34: 257-276 (August 2008).

McLanahan and Jacobsen 2014. Diverging destinies revisited. In Families in an Era of Increasing Inequality (forthcoming 2015). Springer. 
Merz, E.-M. and A. C. Liefbroer 2017. Cross-national differences in the association of educational attainment with completed fertility. Do welfare regimes matter? Vienna Yearbook of Population Research 2017(15): xx-xx.

Miettinen, A., A. Rotkirch, I. Szalma, A. Donno and M. L. Tanturri 2015. Increasing childlessness in Europe: Time trends and country differences. Families and Societies working paper Series N. 33.

Milewski, N. 2007. First child of immigrant workers and their descendants in west Germany: Interrelation of events, disruption, or adaptation? Demographic Research 17(29): 859-896.

Mills, M. and H. P. Blossfeld 2005. Globalization, uncertainty and the early life course. A theoretical framework. In Globalization, Uncertainty and Youth in Society, eds H. P. Blossfeld, E. Klijzing, M. Mills and K. Kurz, 1-24. London: Routledge.

Morgan, S. P. 2003. Low fertility in the twenty-first century. Demography 40(4): 589-603.

Myrskylä, M., H. P. Kohler and F. C. Billari 2009. Advances in development reverse fertility decline. Nature 460(6): 741-743.

Neyer G., J. M. Hoem and G. Andersson 2017. Education and childlessness: The influence of educational field and educational level on childlessness among Swedish and Austrian women. In Childlessness in Europe: Contexts, Causes, and Consequences, eds M. Kreyenfeld and D. Konietzka. Demographic Research Monographs (A series of the Max Planck Institute for Demographic Research). Cham: Springer.

Ní Bhrolcháin, M. and Éva Beaujouan 2012. Fertility postponement is largely due to rising educational enrolment. Population Studies 66(3): 311-327.

OECD 2014. Education at a Glance 2014: OECD Indicators, OECD Publishing. DOI: 10.1787/eag-2014-en.

Parrado, E. A. and S. P. Morgan 2003. Intergenerational fertility among hispanic women: New evidence of immigrant assimilation. Demography 45.

Perelli-Harris, B., W. Sigle-Rushton, M. Kreyenfeld, T. Lappegård, R. Keizer and C. Berghammer 2010.The educational gradient of childbearing within cohabitation in Europe. Population and Development Review 36(4): 775-801.

Pew Research Center 2013. Long-term trend accelerates since recession. Record share of new mothers are college educated. http://www.pewsocialtrends.org/2013/05/10/ record-share-of-new-mothers-are-college-educated/, retrieved November 2015.

Quesnel-Vallée, A. and S. P. Morgan 2003. Missing the target? Correspondence of fertility intentions and behaviour in the U.S. Population Research and Policy Review 22(5-6): 497-525.

Raz-Yurovich, L. 2014. A transaction cost approach to outsourcing by households. Population and Development Review 40(2): 293-309.

Schwartz, C. R. 2010. Earnings inequality and the changing association between spouses' earnings. American Journal of Sociology 115: 1524-1557.

Skirbekk, V. 2008. Fertility trends by social status. Demographic Research 18(5): 145-180.

Skirbekk, V., H. P. Kohler and A. Prskawetz 2004. Birth month, school graduation, and the timing of births and marriages. Demography 41(3): 547-568.

Sobotka, T. 2004. Is lowest-low fertility in Europe explained by the postponement of childbearing? Population and Development Review 30(2): 195-220. 
Sobotka, T. 2008. The rising importance of migrants for childbearing in Europe. Demographic Research 19(9): 225-248.

Sobotka, Tomás, Vegard Skirbekk and Dimiter Philipov 2011. Economic recession and fertility in the developed world. Population and Development Review 37: 267-306.

Stange, Kevin 2011. A longitudinal analysis of the relationship between fertility timing and schooling. Demography 48(3): 931-956.

Stevenson, B. 2008. Divorce law and women's labor supply. Journal of Empirical Legal Studies 5(4): 853-873, December 2008.

Testa, M. R. 2012. Family sizes in Europe: Evidence from the 2011 Eurobarometer survey. European demographic research paper 2. Vienna institute of demography, Austrian academy of sciences.

Testa, Maria Rita 2014. On the positive correlation between education and fertility intentions in Europe: Individual-and-country-level evidence. Advances in Life Course Research 21: 28-42.

Torr, B. M. and S. E. Short 2004. Second births and the second shift: A research note on gender equity and fertility. Population and Development Review 30(1): 109-130.

Toulemon, L. 2004. Fertility among immigrant women, new data, a new approach. Population $\mathcal{E}$ Societies 400(April 2004): 1-4.

U.S. Census Bureau 2014. Fertility of women in the united states: 2012. Population Characteristics, Report by Monte, Lindsay M. and Renee R. Ellis.

Van Bavel, J. 2012. The reversal of gender inequality in education, union formation and fertility in Europe. Vienna Yearbook of Population Research 2012: 127-154.

Van Bavel, J. 2014. The mid-twentieth century baby boom and the changing educational gradient in Belgian cohort fertility. Demographic Research 30(33): 925-962.

Willis, R. 1974. Economic theory of fertility behavior. In Economics of the Family: Marriage, Children and Human Capital, ed. Schultz, 25-80, UMI, NBER. 